\title{
Leadership Development Among a Cohort of Undergraduate Interdisciplinary Students in the Health Professions
}

\author{
Nicole S. McKinney, MA, PhD(c) \\ Doctoral Candidate \\ Drexel University \\ Roberta Waite, EdD, PMHCNS-BC, FAAN, ANEF \\ Professor \\ Drexel University
}

\begin{abstract}
Leadership content and pedagogical strategies are fundamental to health professionals' education. All health professionals must be able to lead effectively and thrive in today's complex health systems. Students must be involved in meaningful didactic and experiential leadership development early in their academic progression, and educators are positioned to lead in this initiative. This paper describes pre-postfindings from an application of Kouzes and Posner's Student Leadership Practices Inventory with students who completed an interdisciplinary undergraduate leadership development program and observers' perspectives of these students' leadership characteristics. Outcome data found positive change in pre-post data except for encourage the heart for the student participants and challenges others for the observers. Critical reflection and authentic assessment of actions that occurred during the leadership program could have shifted students' realization of behaviors they actually did not demonstrate as originally thought at the beginning of the program. Observers' scores tended to be higher than students' scores; however, minimal change in posttest scores could be attributed to not using the same observers for the pre and post assessments.
\end{abstract}

\section{Introduction}

The dynamics of healthcare necessitate enhanced leadership qualities among health professionals in order to become more adept at working efficiently as individuals, as well as collaboratively with interdisciplinary teams. Scholars recognized that a serious gap in mobilizing effective care to be delivered in teams relates to how students in the health professions have been educated in silos hindering their ability to learn about interdisciplinary team leadership (Careau et al., 2014; MacPhee, Chang, Lee, and Spiri' 2013). Thibault (2013) found that the silo approach lacked success as a result of "attitudinal biases, lack of understanding of others' professional roles and expertise, and an absence of the competencies needed for effective teamwork and collaborative practice" (p. 1929). Moreover, for optimal function to occur within these care teams, students could benefit from gaining leadership developmental skills earlier in their 
academic careers.

Coltart and colleagues (2012) reported that enhanced leadership competencies among care team members could lead to high-performing health-care systems contributing to improved health care quality and safety, enhanced performance, and better engagement among staff. These changes are quite often driven by an individual's behavior, relationships with others, and adeptness at developing, inspiring, and motivating others to strive for more than they had ever planned (Janke, Traynor, \& Boyle, 2013). To be able to affect positive change, fundamental insights regarding consciousness of self among students is requisite, and the level of courage required to fully embrace this charge takes humility (Janke et al., 2013).

\section{Methods}

This non-experimental survey study examined changes in leadership skills and competencies among a cohort of undergraduate students who were enrolled in an interdisciplinary 9-month leadership program (Waite, McKinney, Glasgow, \& Meloy, 2014). Implications for both professional leadership and education will also be discussed. Prior to initiating this study, the University's institutional review board provided clearance. This study occurred between September 2013 and June 2014 with outcomes derived from the Kouzes and Posner Student Leadership Practices Inventory (SLPI; 2006). Design of the original 9 month Leadership Program is described elsewhere (Waite, McKinney, Glasgow, \& Meloy, 2014); your study is guided by the Kouzes and Posner Framework using a social justice lens.

The curriculum engaged interdisciplinary students over the course of nine months where they participated in three consecutive courses (fall, winter, and spring quarters). Course content from each of the three courses built on the previous one. The first course focused on consciousness of self and leadership philosophy. Students gained a deeper awareness of their emotions, biases, thoughts, ethics, values, and personal experiences while also considering their positioning in society, gleaning how power and privilege influence how their voices are heard and how their identities shape their decision-making processes. They also reflected on how these factors shaped their leadership philosophy.

The second course focused on group dynamics and leading teams. Students examined aspects of group development and factors that contribute to mobilizing teams effectively (e.g., conflict management, effective communication, and planning). They also took into consideration how prejudice, privilege, stereotyping, oppression, social identity, and individual personalities, talents, and personal agenda's affect attaining teamrelated goals.

The third course focused on community health and leadership. Students examined the socio-determinants of health, sources of power and inequalities in the community, and the power of community organizing and community building to promote health. The following are examples of pedagogical strategies used to facilitate student learning: reflective exercises, leadership briefs, group debates, engaging guest and panel speakers, 
individual and team projects, service learning projects, peer evaluation, diversity and privilege exercises, fishbowl activities, cultural autobiography, mind mapping, and action plan projects.

Participants and Setting. Undergraduate students $(\mathrm{N}=18)$ from varied disciplines (nursing, health services administration, and health sciences) participated in the research study. The convenience non-random sample of participants included 17 women and one man, all of whom attended an academic institution located in the northeastern region of the United States (US). Students engaged in this program while completing their traditional academic courses required for completion of their respective majors. In addition to the student participants, numerous observers (persons who knew students well, i.e. educators, employers, supervisors) also participated in the research study. The observers' role was to give perceived subjective feedback of the observed leadership skills and behaviors that the students demonstrated during their engagement in the three courses.

Assessment Measure: Kouzes and Posner SLPI. We used the evidenced-based Student Leadership Practices Inventory 360 (SLPI) (henceforth SLPI), co-designed by James M. Kouzes and Barry Z. Posner (2006), to measure the participants' personal leadership skills. The self-report SLPI is a 30-item behavioral assessment that concentrates on five practices of exemplary leadership: (1) model the way-confirming values and affirming shared ideals; (2) inspire a shared vision - envisioning the future by incorporating a vision that includes all parties involved; (3) challenge the process fostering risks, innovative ways of improvement by reflecting on experiences; (4) enable others to act - trust and relationship building; and (5) encourage the heartdemonstrating appreciation, celebrating the values and victories of the working team (Dunn, Dastoor \& Sims, 2012; Posner, 2013).

Many scholars have reported the SLPI as having high internal reliability (.75 to $.96)$ and test-retest reliability (.90 and above), with strong content validity, high face validity, good construct, concurrent validity, and predictive validity and as having valid psychometric properties (Foli, Braswell, Kirkpatrick, \& Lim, 2014; Krugman, Heggem, Kinney, \& Frueh, 2013; Lee \& Cummings, 2008; Martin, McCormack, Fitzsimons, \& Spirig, 2012; Posner, 2009). The 30-item Kouzes and Posner SLPI (2006) assessment is scored on a five point Likert scale ranging in responses from: 1 (rarely or seldom), 2 (once in a while), 3 (sometimes), 4 (often), and 5 (very frequently). The average duration timeframe to complete the assessment is 10-20 minutes. The responses address topics regarding how frequently the student participants self-reported their engagement of leadership behaviors associated with the five exemplary practices (Posner, 2009). In addition, observers' perceptions of the student participants' demonstration of these behaviors was also measured using the same Kouzes and Posner SLPI for their assessment of each of the students.

Analysis. The 18 undergraduate student participant' voluntarily completed the self-report questionnaire pretest (September 2013) and posttest (June 2014); the observers also completed their assessments based on these same beginning and ending 
observations. After the student participants and observers completed the assessments, the results were hand-scored by the researchers following SLPI guidelines as specified in the instruction manual.

The research data was coded numerically using the SPSS (Statistical Package of Social Sciences) 20.0 database for the SLPI measure and reported in aggregate form in order to preserve the student participants' and observers' confidentiality. There were different numbers of observers for the pre- and posttests; therefore, we averaged the means when analyzing the data. We used a paired sample t-test to determine whether there was statistical significance among student participants' specific leadership behaviors and skills at time one (pretest) September 2013 and time two (posttest) June 2014. Likewise, the observers' perceptions of the student participants' leadership qualities, effectiveness, and practices were also measured using a paired sample t-test.

\section{Results}

Student Participant SLPI Results. The pretest and posttest outcome data of the 18 student participants' overall means scores for each of the five exemplary leadership practices include can be viewed in Table 1. 
Table 1: Kouzes \& Posner 2013-2014, Pre-Post Assessment Summary Results

\begin{tabular}{|c|c|c|c|c|c|c|}
\hline & \multicolumn{2}{|c|}{ Means } & \multicolumn{2}{|r|}{$S D$} & \multicolumn{2}{|c|}{ Significance } \\
\hline & Pre & Post & Pre & Post & Corr & 2-tailed t-test \\
\hline \multicolumn{7}{|l|}{ MODELS THE WAY } \\
\hline Models personal example & 4.28 & 4.33 & .67 & .69 & .427 & .749 \\
\hline Holding others accountable & 3.67 & 3.78 & .69 & .65 & .088 & .607 \\
\hline Exhibits reliability & 4.72 & 4.39 & 1.07 & .78 & .240 & $.029 *$ \\
\hline Demonstrates self-awareness & 3.27 & 3.44 & .80 & .68 & .194 & .564 \\
\hline Ability to mediate & 3.94 & 3.89 & .80 & .68 & .205 & .805 \\
\hline Expresses values & 2.94 & 3.50 & .94 & .92 & $.034 *$ & .086 \\
\hline \multicolumn{2}{|c|}{ **Models The Way average of means } & \multicolumn{3}{|c|}{$3.80 \quad 3.89$} & & \\
\hline \multicolumn{7}{|l|}{ INSPIRE A SHARED VISION } \\
\hline Communicates beliefs & 4.06 & 3.61 & .73 & .98 & .115 & .119 \\
\hline Capability to describe & 3.61 & 3.89 & .98 & .58 & .126 & .288 \\
\hline Expresses vision & 3.72 & 3.67 & .75 & .77 & -.170 & .842 \\
\hline Verbalizes personal interests & 3.22 & 3.39 & .88 & .85 & $-.044 *$ & .579 \\
\hline Optimistic & 4.39 & 4.33 & .85 & .69 & .673 & .717 \\
\hline Passionate & 3.44 & 3.78 & .92 & .89 & .202 & .231 \\
\hline \multicolumn{5}{|c|}{ **Inspire A Shared Vision average of means $\quad 3.74 \quad 3.78$} & & \\
\hline \multicolumn{7}{|l|}{ CHALLENGE THE PROCESS } \\
\hline Challenges others & 4.17 & 4.11 & .71 & .58 & .238 & .772 \\
\hline Inquisitive & 3.22 & 3.56 & .73 & .71 & $-.025^{*}$ & .187 \\
\hline Innovative & 3.72 & 4.00 & .96 & .67 & .358 & .236 \\
\hline Learns from experience & 3.94 & 3.72 & .80 & .89 & .633 & .215 \\
\hline Flexible & 3.94 & 3.83 & .80 & .62 & .336 & .579 \\
\hline Initiates experiments & 3.61 & 3.50 & 61 & .79 & .062 & 631 \\
\hline \multicolumn{5}{|c|}{ **Challenge The Process average of means $\quad 3.77 \quad 3.79$} & & \\
\hline \multicolumn{7}{|l|}{ ENABLE OTHERS TO ACT } \\
\hline Fosters relationship building & 4.22 & 4.33 & .65 & .77 & .553 & .495 \\
\hline Opened minded & 4.28 & 4.22 & .67 & .81 & .532 & .749 \\
\hline Respectful & 4.72 & 4.72 & .46 & .57 & .802 & 1.000 \\
\hline Supportive & 3.78 & 3.89 & .65 & .47 & .107 & .542 \\
\hline Trusting & 4.06 & 4.06 & .64 & .87 & .100 & 1.000 \\
\hline Promotes team building & 3.33 & 4.00 & .84 & .59 & .589 & $.001 *$ \\
\hline \multicolumn{3}{|c|}{ **Enable Others To Act average of means } & 4.07 & 4.20 & & \\
\hline \multicolumn{7}{|l|}{$\begin{array}{l}\text { ENCOURAGE THE HEART } \\
\text { THE }\end{array}$} \\
\hline Complimentative & 4.33 & 3.94 & .49 & .64 & .253 & $.030 *$ \\
\hline Encourages others & 4.22 & 4.11 & .55 & .58 & .286 & .495 \\
\hline Expresses appreciation & 4.44 & 4.11 & .51 & .58 & .614 & $.010 *$ \\
\hline Publicly recognizes others & 3.67 & 3.50 & .91 & .92 & .421 & .483 \\
\hline Celebrates & 3.78 & 3.67 & .73 & .69 & .312 & .579 \\
\hline Creatively recognizes others & 3.61 & 3.50 & .98 & .71 & .468 & .607 \\
\hline \multicolumn{3}{|c|}{ **Encourage The Heart average of means } & 4.01 & 3.81 & & \\
\hline $\begin{array}{l}\mathrm{N}=18 \text { participants } \\
1=\text { Rarely, } 2=\text { Once in a wl } \\
* \text { Correlation is significant }, \\
* * \text { Overall average of means }\end{array}$ & 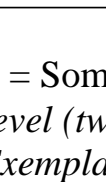 & $T$ & & $-p$ & fre & \\
\hline
\end{tabular}


All of the students' mean scores, with the exception of one score (expresses values), confirmed "sometimes" or "often" as the self-assessment. The exception score, expresses values, is a subcategory associated with the exemplary leadership practice models the way and is defined as the participants' abilities to articulate their values. The average mean scores for expresses values, of the student participants' reported an increase in articulation of values from "once in a while" in the pretest to "sometimes" in the posttest. Similarly, the average mean scores for innovative and promotes team building of the student participants indicated a shift from "sometimes" to "often" between pretest and posttest results. However, communicates beliefs and complimentative average scores of means for student participants demonstrated a change from "often" in pretest to "sometimes" in posttest results.

Paired sample correlations indicated statistical significance at the $p<.05$ level for expresses values, verbalizes personal interest, and inquisitive. In addition, paired sample correlation demonstrated negative correlations for verbalizes personal interest, expresses vision, and inquisitive. Furthermore, there was statistical significance at the $p<.05$ level (two-tailed) for exhibits reliability, promotes team building, complimentative, and expresses appreciation within the outcome data.

All of the observers' means scores affirmed "often" performance for participants with the exception of one score (challenges others) that showed a confirmed decline from a low "often" to a high "sometimes" choice response between pretests and posttests. Combined, the pretest and posttest overall average of means scores for each of the five exemplary leadership practices for observers are represented in Table 2. A paired sample correlation denoted statistical significance at the $p<.05$ level for the behavioral statements of expresses values and respectful. There were no statistically significant outcome results at the $p<.05$ level (two-tailed) for any leadership action statements as reported by the observers or the participants.

Table 2: Kouzes \& Posner 2013-2014, Pre-Post Observers' Assessment Summary Results

\begin{tabular}{lcccccc}
\hline & \multicolumn{2}{c}{ Means } & \multicolumn{2}{c}{ SD } & \multicolumn{3}{c}{ Significance } \\
& Pre & Post & Pre & Post & Corr & 2-tailed t-test \\
\hline MODELS THE WAY & & & & & & \\
Models personal example & 4.45 & 4.38 & .28 & .55 & .548 & .634 \\
Holding others accountable & 4.26 & 4.17 & .36 & .71 & .646 & .625 \\
Exhibits reliability & 4.68 & 4.69 & .29 & .32 & .733 & .910 \\
Demonstrates self-awareness & 4.26 & 4.28 & .40 & .57 & .596 & .925 \\
Ability to mediate & 4.35 & 4.31 & .30 & .53 & .224 & .812 \\
Expresses values & 4.16 & 4.23 & .42 & .46 & $.026 *$ & .717 \\
$* *$ Models The Way average of means & $\mathbf{4 . 3 6}$ & $\mathbf{4 . 3 4}$ & & & & \\
\hline INSPIRE A SHARED VISION & & & & & & \\
Communicates beliefs & 4.37 & 4.39 & .36 & .38 & .708 & .866 \\
Capability to describe & 4.26 & 4.18 & .28 & .56 & .852 & .570 \\
Expresses vision & 4.26 & 4.23 & .34 & .57 & .887 & .863 \\
Verbalizes personal interests & 4.04 & 4.00 & .46 & .79 & .597 & .847 \\
\hline
\end{tabular}




\begin{tabular}{|c|c|c|c|c|c|c|}
\hline $\begin{array}{l}\text { Optimistic } \\
\text { Passionate } \\
\text { **Inspire A Shared Vision average of means }\end{array}$ & $\begin{array}{l}4.77 \\
4.36 \\
\mathbf{4 . 3 4}\end{array}$ & $\begin{array}{l}4.47 \\
4.41 \\
\mathbf{4 . 2 8}\end{array}$ & $\begin{array}{l}.24 \\
.34\end{array}$ & $\begin{array}{l}.65 \\
.69\end{array}$ & $\begin{array}{l}.638 \\
.540\end{array}$ & $\begin{array}{l}.071 \\
.724\end{array}$ \\
\hline \multicolumn{7}{|l|}{ CHALLENGE THE PROCESS } \\
\hline Challenges others & 4.06 & 3.98 & .49 & .81 & .637 & .729 \\
\hline Inquisitive & 4.11 & 4.14 & .49 & .64 & .830 & .845 \\
\hline Innovative & 4.19 & 4.19 & .32 & .70 & .625 & 1.000 \\
\hline Learns from experience & 4.03 & 4.15 & .41 & .52 & .892 & .436 \\
\hline Flexible & 4.32 & 4.58 & .27 & .45 & .755 & .057 \\
\hline Initiates experiments & 4.22 & 4.44 & .41 & .38 & .274 & .065 \\
\hline **Challenge The Process average of means & 4.16 & 4.25 & & & & \\
\hline \multicolumn{7}{|l|}{ ENABLE OTHERS TO ACT } \\
\hline Fosters relationship building & 4.59 & 4.42 & .32 & .54 & .824 & .245 \\
\hline Opened minded & 4.61 & 4.59 & .31 & .52 & .500 & .900 \\
\hline Respectful & 4.79 & 4.77 & .29 & .37 & $.003^{*}$ & .744 \\
\hline Supportive & 4.44 & 4.38 & .25 & .60 & .106 & .727 \\
\hline Trusting & 4.31 & 4.41 & .43 & .44 & .158 & .538 \\
\hline Promotes team building & 4.37 & 4.19 & .28 & .55 & .583 & .277 \\
\hline$*_{\text {Enable Others To Act } \text { average of means }}$ & 4.52 & 4.46 & & & & \\
\hline \multicolumn{7}{|l|}{ ENCOURAGE THE HEART } \\
\hline Complimentative & 4.46 & 4.51 & .38 & .38 & .981 & .695 \\
\hline Encourages others & 4.63 & 4.47 & .31 & .51 & .407 & .221 \\
\hline Expresses appreciation & 4.68 & 4.51 & .26 & .71 & .818 & .372 \\
\hline Publicly recognizes others & 4.30 & 4.35 & .37 & .50 & .767 & .730 \\
\hline Celebrates & 4.41 & 4.21 & .29 & .74 & .585 & .335 \\
\hline Creatively recognizes others & 4.21 & 4.14 & .46 & .73 & .657 & .734 \\
\hline **Encourage The Heart average of means & 4.45 & 4.37 & & & & \\
\hline
\end{tabular}

Observers of the program's student participants $(\mathrm{N}=18)$

$1=$ Rarely, $2=$ Once in a while, $3=$ Sometimes, $4=$ Often, $5=$ Very frequently

*Correlation is significant, 0.05 level (two-tailed) for all pre-postmeasures

**Overall average of means for Exemplary Leadership Practice

\section{Discussion and Limitations}

Enhancing self-awareness about leadership abilities as well as purposeful development of leadership is a skill that needs to be cultivated and practiced (Nagy \& Edelman, 2014). Astin and colleagues (2000) reported that leadership must be engaged as an active tool rather than passive lens, as "students will implicitly generate their notions and conceptions of leadership from what is taught intentionally and unintentionally across the educational experience (p. vi)." Therefore, leadership and educators within postsecondary settings must impart leadership as an action instead of merely a frame of reference; specifically, leadership ought to be treated as a fundamental component of learning (Nagy \& Edelman, 2014). Nevertheless, Vasbinder (2012) noted that while there are numerous thoughts about why leadership development is important, within postsecondary settings, particularly for undergraduate students, assessment of leadership 
is scarce. Thus, it is not surprising that these very settings typically have failed to generate adequately prepared leaders in the business and/or health professions.

Intentional and early development of greater self-awareness in employing the behavioral skills of leadership is requisite (Vasbinder, 2012).

This study showed statistical significance for student responses using paired sample correlations at the $p<.05$ level for expresses values, verbalizes personal interest, and inquisitive. Statistical significance at the $p<.05$ level (two-tailed) for exhibits reliability, promotes team building, complimentative, and expresses appreciation within the outcome data. With observers, less change was found; a paired sample correlation denoted statistical significance at the $p<.05$ level for the behavioral statements of expresses values and respectful. However, it was discovered that the same observers (prepost) were not used with some participants, and this could have affected differences in scoring their assessments. Moreover, with only slight changes and the one shift downward (encourage the heart), consideration must be given to students' newfound insights about their leadership behaviors after having engaged in leadership experiences during the program. For example, Romsa (2013) suggested that students might overrate their leadership behaviors on the pretest when they lack leadership experiences. Specifically, not having been in a situation where they could demonstrate that behavior, the student may have thought that he or she would often encourage the heart. During the leadership program with critical reflection and authentic assessment of actions, students interacting with their peers may have realized this was actually not a frequent behavior demonstrated as originally thought at the beginning of the three courses. This could have reflected the shift when they took the posttest, where they rated their leadership behaviors genuinely after having just completed the leadership program.

The success of this program is similar to that of other programs. Vasbinder (2012) reported that "exposure to new learning by diverse health care experts and thought leaders, increased awareness of topics and actions relevant to effective (p. 24)" leadership in the health professions, and engagement with pertinent literature that increased knowledge and understanding of vital issues that are significant in health care leadership. This study's program is different from other programs in several ways : 1) it engages students at the undergraduate level over the course of 9 months while students concurrently completed required academic courses for their major instead of using a stand-alone workshop for a very short period of time; 2) it is interdisciplinary rather than focused on a singular profession (silos), which promotes working relations among distinct groups of students in the health professions; and 3) it used a social justice lens to bring forth explicit attention to factors related to power, privilege, and oppression among the content shared and discussed which is often negated when learning about leadership.

Several limitations of this study must be noted. The sample of students was recruited from a private university located in the northeastern region of the US. The experiences of these undergraduate students from the nursing, health sciences, and health services administration programs may differ from other cohorts of students in this college and from students who did not voluntarily participate in this program while concomitantly taking their routine academic courses. There was no control group. Also, 
this was a small sample size including only 18 students and not all students used the same observers for pretest/posttest assessment. Lastly, no qualitative data was used, only quantitative assessment data was captured from Kouzes and Posner's assessment findings from students and selected observers.

\section{Implications for Leaders and Educators}

Indispensable skills needed within our contemporary health care environment require that students in the health professions gain leadership competencies that extend beyond memorization of leadership theories and budget management. Intentional cultivation of leadership skills through practice and actionable means such as implementation of Kouzes and Posner's five practices of exemplary leadership is key. Educators must examine where in the curriculum leadership content is embedded and how operationalization of content occurs, particularly with use of application exercises within varied contexts. It is beneficial to focus on self-awareness, teamwork/group dynamics, as well as community-oriented leadership competencies given that leadership is not just about self, rather it is about how a person engages effectively with others.

Educators must realize that planning what goes into their students' learning experiences serves as the cornerstone for building students' confidence. They depend on what they learn from their limited undergraduate experience when they: 1) enter the health care environment and function on diverse teams in meaningful ways, and 2) undertake leadership roles early in their professional careers. Therefore, positioning students in activities and learning environments that reflect the groups of professionals with whom they will be working in the future is both practical and prudent.

Highly efficient collaborative teams do not occur by chance; therefore, increasing awareness for students and initiating demonstration and practice of basic skills early on is important. Educators who strive to promote leadership skills to prepare students now and in the future recognize that successful interdisciplinary healthcare teams require competent leadership in each discipline. In addition, critical to the success of these teams is the importance of interdisciplinary respect and opportunity for trust to form between individuals and across the team. Use of a structure such as the undergraduate interdisciplinary program discussed in this study could help to cultivate these competencies at the undergraduate level by intentionally learning about roles and skills of others and engaging in interdisciplinary programs of study and personal reflection (St George, 2013).

\section{Conclusion}

Kouzes and Posner (2006) contend that leadership practices can be learned, and it is incumbent upon educators to actively implement curriculum experiences that support these efforts in order to address the needs of changing multifaceted healthcare systems effectively. Harnessing the leadership capacity of students in the varied health professions not only encourages collaborative interrelationships and transcends single perspectives and discipline boundaries, it also promotes investment in human capital- 
our students. Careau and colleagues (2014), however, reported that students in the health professions continue to have limited interaction between each other as well as faculty across health disciplines. Leaders within postsecondary settings as well as educators must revisit the necessary competencies to provide leadership in the $21^{\text {st }}$ century's healthcare environment and champion necessary changes. Ultimately, intentional efforts placed on surveying curricula and pedagogic strategies used to teach students in the health professions must be scaled to a level that prepares them for the leadership challenges forthcoming in their professional careers.

\section{References}

Astin, A. W., Astin, H., Allen, K. E, Burkhardt, J. C., Cress, C., Flores, R. A., ...... Zimmerman-Oster, K. A. (2000). Leadership reconsidered: Engaging higher education in social change. Educational Leadership and Policy. Retrieved from http://www.naspa.org/images/uploads/kcs/SLPKC_Learning_Reconsidered.pdf

Careau, E., Biba, G., Brander, R., Van Dijk, J. P., Verma, S., Paterson, M., \& Tassone, M. (2014). Health leadership education programs, best practices, and impact on learners' knowledge, skills, attitudes, and behaviors and system change: A literature review. Journal of Healthcare Leadership, 6, 39-50.

Coltart, C. E. M., Cheung, R., Ardolino, A., Bray, B., Rocos, B., Bailey, A....Donaldson, L. (2012). Leadership development for early career doctors. The Lancet, 379(9828), 1847-1849. doi:10.1016/S0140-6736(12)60271-2

Dunn, M. W., Dastoor, B., \& Sims, R. L. (2012). Transformational leadership and organizational commitment: A cross-cultural perspective. Journal of Multidisciplinary Research, 4(1), 45-60.

Foli, K. J., Braswell, M., Kirkpatrick, J., \& Lim, E. (2014). Development of leadership behaviors in undergraduate nursing students: A service-learning approach. Nursing Education Perspectives, 35(2), 76-82.

Janke, K. K., Traynor, A. P., \& Boyle, C. J. (2013). Competencies for students' leadership development in doctor of pharmacy curricula to assist curriculum and leadership instructors. American Journal of Pharmaceutical Education, 77(10), 222-231.

Kouzes, J. M., \& Posner, B. Z. (2006). Student leadership practices inventory: Self. San Francisco, CA: Jossey-Bass.

Krugman, M., Heggem, L., Kinney, L. J., \& Frueh, M. (2013). Longitudinal charge nurse leadership development and evaluation. The Journal of Nursing Administration, 43(9), 438-446. doi:10.1097/NNA.0b013e3182a23b26 
Lee, H., \& Cummings, G. G. (2008). Examining relationships between director leadership practices and manager worklife and burnout. Journal of Leadership Studies, 2(2), 47-62.doi:10.1002/j1s.20061

MacPhee, M., Chang, L., Lee, D., \& Spiri, W. (2013). Global health care leadership development: Trends to consider. Journal of Healthcare Leadership, 5, 21-29.

Martin, J. S., McCormack, B., Fitzsimons, D., \& Spirig, R. (2012). Evaluation of a clinical leadership programme for nurse leaders. Journal of Nursing Management, 20(1), 72-80. doi:10.1111/j.1365-2834.2011.01271.x

Nagy, B., \& Edelman, D. (2014) Transformational leadership in planning curricula. Current Urban Studies, 2, 198-211.

Posner, B. Z. (2009). A longitudinal study examining changes in students' leadership behavior. Journal of College Student Development, 50(5), 551-563. doi:10.1353/csd.0.0091

Posner, B. Z. (2013). It's how leaders behave that matters, not where they are from. Leadership \& Organization Development Journal, 34(6), 573-587.

Romsa, B. (2013). Undergraduate sport management students ' perceptions of leadership behaviors through service learning: A quantitative, quasi-experimental study. (Dissertation). Retrieved from http://cornerstone.lib.mnsu.edu/cgi/viewcontent.cgi?article=1091\&context=etds

St George, I. (12.). (2013). Cole's Medical practice in New Zealand. New Zealand: Medical Council of New Zealand.

Thibault, G. (2013). Reforming health professions education will require culture change and closer ties between classroom and practice. Health Affairs, 32(11), 19281932.

Vasbinder, W. (2012). Student and faculty perceptions of elements of the college experience that foster students' leadership development. (Dissertation). Retrieved from http://media.proquest.com/media/pq/classic/doc/2667929341/fmt/ai/rep/NPDF?_s $=$ rTqeOZ\%2Bjo3JIVcG0omLzIEXKRfw\%3D

Waite, R., McKinney, N., Glasgow, M., \& Meloy, F. (2014). The embodiment of authentic leadership. Journal of Professional Nursing, 30(4), 282-291. 


\section{Author Biographies}

Nicole S. McKinney, MA, PhD(c) (nm566@drexel.edu) is a doctoral candidate in Couple \& Family Therapy at Drexel University located in Philadelphia, PA.

Dr. Roberta Waite (rlw26@drexel.edu) has been a registered nurse for 27 years with clinical, administrative, and academic experience. She has been in higher education for 12 years with specific clinical interest in mental/ behavioral health research and educational research focuses on interprofessional leadership development among students in the health professions. 